Article

\title{
Trends in Magnesium Intake among Hispanic Adults, the National Health and Nutrition Examination Survey (NHANES) 1999-2014
}

\author{
Jialiang Liu ${ }^{1}$, Yuhan Huang ${ }^{1}$, Qi Dai ${ }^{2}$, Kimberly G. Fulda ${ }^{3}$, Shande Chen ${ }^{4}$ and \\ Meng-Hua Tao ${ }^{1, * \mathbb{D}}$ \\ 1 Department of Biostatistics and Epidemiology, University of North Texas Health Science Center, Fort Worth, \\ TX 76107, USA; Jialiang.Liu@live.unthsc.edu (J.L.); yuhan24@outlook.com (Y.H.) \\ 2 Department of Medicine, Division of Epidemiology, Vanderbilt Epidemiology Center, Vanderbilt University \\ School of Medicine, Vanderbilt-Ingram Cancer Center, Vanderbilt University Medical Center, Nashville, \\ TN 37203, USA; qi.dai@vanderbilt.edu \\ 3 Department of Family Medicine and Osteopathic Manipulative Medicine; NorTex, University of North Texas \\ Health Science Center, Fort Worth, TX 76107, USA; kimberly.fulda@unthsc.edu \\ 4 Graduate School of Biomedical Sciences, University of North Texas Health Science Center, Fort Worth, \\ TX 76107, USA; Shande.Chen@unthsc.edu \\ * Correspondence: menghua.tao@unthsc.edu; Tel.: +1-817-735-0520
}

Received: 25 October 2019; Accepted: 19 November 2019; Published: 22 November 2019

\begin{abstract}
This study aimed at examining trends in magnesium intake among U.S. Hispanic adults stratified by gender, Hispanic origins, age, and poverty income ratio (PIR) level. Data on 9304 Hispanic adults aged $\geq 20$ years from eight National Health and Nutrition Examination Survey (NHANES) cycles (1999-2014) were included in this study. For each cycle, survey-weighted mean dietary and total magnesium intakes were estimated. The prevalence of dietary and total magnesium intake below the Recommended Dietary Allowance (RDA) was further estimated stratified by gender and age groups. Linear regression was used to test trend. Over the survey cycles, both dietary and total magnesium intakes were significantly increased among Hispanic adults. In the study period, magnesium intake tended to be lower in females, adults in other Hispanic-origin group, those aged $\geq 65$ years old, and those with a PIR $<1.0$. The prevalence of magnesium intake inadequacy decreased among Hispanic adults; however, more than $70 \%$ of Hispanic males and females continued to have magnesium intake below the RDA in 2013-2014. From 1999/2000 to 2013/2014, despite several improvements in magnesium intake having been identified, additional findings showed insufficient intake in Hispanic males and females, suggesting the need to improve magnesium intake through diet and dietary supplementation for U.S. Hispanics.
\end{abstract}

Keywords: magnesium intake; Hispanic adults; trends; gender

\section{Introduction}

Magnesium, an essential mineral, plays an important role in hundreds of physiologic activities, including energy production, lipid and glucose metabolism, and inflammation [1,2]. Magnesium is also involved in bone metabolism and the maintenance of physiological functions of bone and muscle $[3,4]$. Approximately $60 \%$ of total magnesium in the body is stored in bone, suggesting the importance of magnesium to the skeletal system [5]. Natural sources of magnesium include leafy green vegetables, whole grain, nuts, and milk products [6,7]. Inadequate dietary magnesium intake has been linked to various adverse health outcomes [2,6], including metabolic syndrome [8-10], type 2 diabetes [11,12], cardiovascular disease (CVD) [13,14], osteoporosis [15], and possibly some cancers [16,17]. 
The Recommended Dietary Allowance (RDA) for magnesium from all sources represents the average daily intake level that meets sufficient requirement for nearly all ( $97 \%$ to $98 \%$ ) healthy individuals in a particular gender and life stage group [6]. For adults in the United States (U.S.), the RDA for magnesium is $400 \mathrm{mg} /$ day for males aged 19-30, $420 \mathrm{mg} /$ day for males ages 30 and over, $310 \mathrm{mg} /$ day for females aged 19-30, and $320 \mathrm{mg} /$ day for females ages 30 and over [6]. Previous surveys have shown that magnesium intake has been historically low in the U.S. population [1,18]. The 2001-2008 National Health and Nutrition Examination Survey (NHANES) showed that over $50 \%$ of the adult population did not consume the recommended magnesium intake regardless of their weight status [18]. The 2015-2020 Dietary Guideline for Americans particularly identified magnesium as one of the shortfall nutrients [19].

In the U.S., the Hispanic population constitutes the youngest and rapidly growing racial/ethnic group [20,21]. The Hispanic population is estimated to increase to 132.8 million ( $30 \%$ of the U.S. population) in 2050, with the largest increase in Mexican Americans [22]. Moreover, Hispanic adults have a higher prevalence of metabolic syndrome [23] and diabetes mellitus [24] than non-Hispanic whites. However, current knowledge about the status of magnesium intake in this population remains very limited. There is a critical need to understand trends in magnesium intake and corresponding disparities in the U.S. Hispanic population, which may contribute to inform priorities to improve diets, promote healthy diet behavior, as well as to prevent associated health consequences.

In the present study, data from the NHANES 1999-2014 were used to examine trends in dietary and total magnesium intake among U.S. Hispanic adults stratified by gender, ethnicity origins, age, and poverty income ratio (PIR) level. Additionally, the temporal trends in the prevalence of total magnesium intake below the RDA were evaluated among Hispanic adults by gender and age group.

\section{Materials and Methods}

\subsection{Study Population}

Data from eight continuous cycles of the National Health and Nutrition Examination Survey (NHANES) between 1999 and 2014 were used in this study. The NHANES is a cross-sectional survey designed to monitor the health and nutritional status of a nationally representative sample of the noninstitutionalized civilian U.S. population [25]. The NHANES data are released every two years by the U.S. National Center for Health Statistics (NCHS) of the Centers for Disease Control and Prevention [25]. Our study population included adults aged $\geq 20$ years at the time of the survey, who self-identified as Mexican Americans or other Hispanic race/ethnicity, and with at least 1 valid $24 \mathrm{~h}$ dietary recall determined by the NCHS $(n=10,423)$. Pregnant or lactating females and respondents who had missing data for magnesium intake were excluded from the analysis. Finally, a total of 9304 participants were included in this analysis. The sample size per cycle ranged from 911 to 1603 . All participants provided written informed consent, and the Research Ethics Review Board at the (NCHS) approved the survey protocol [25].

\subsection{Assessments of Magnesium Intake}

Details of the protocol and dietary data collection methods are fully described elsewhere [26]. Briefly, daily dietary magnesium intake information was obtained through $24 \mathrm{~h}$ recall interviews using the U.S. Department of Agriculture's Automated Multiple-Pass method [27,28]. Prior to 2003, the NHANES only collected dietary intake with one $24 \mathrm{~h}$ dietary recall for all participants. From 2003, the NHANES collected two $24 \mathrm{~h}$ recalls for each participant. The first dietary recall was collected in person by trained interviewers in NHANES mobile examination centers (MEC). The second dietary recall was completed by telephone 3-10 days after the MEC interview [29]. Dietary supplement information was collected during the household interview, and since 2007, was collected in two $24 \mathrm{~h}$ recalls, as a part of the Dietary Supplement Questionnaire [26]. Information included the participant's use of vitamins, minerals, and other dietary supplements over the past 30 days [26]. Moreover, information about 
type, consumption frequency, duration, and amount taken was also collected for each reported dietary supplement [26]. The average daily magnesium intake from dietary supplements was calculated for participants using the number of days supplement use was reported, the reported amount taken per day, and the serving size unit from the product label [28]. Total magnesium intake was calculated by summing intakes from diet and supplements.

\subsection{Statistical Analysis}

All statistical analyses were conducted in SAS software (version 9.4, SAS Institute, Cary, NC, USA) using the "Survey" procedures to incorporate the complex, multistage survey sampling design of the NHANES. Survey-weighted means and standard errors (SE) for dietary and total magnesium intakes were estimated for each NHANES cycle among all Hispanic adults, as well as subpopulations stratified by age (i.e., 20-34, 35-49, 50-64, and $\geq 65$ years), gender, ethnicity origins (i.e., Mexican American, other Hispanic), and PIR level (i.e., $<1.0,1.0-1.84$, and $\geq 1.85$ ). The prevalence of magnesium intake below the RDA was estimated stratified by gender and age groups for each NHANES cycle between 2003 and 2014 which had two nonconsecutive $24 \mathrm{~h}$ recalls using the established National Cancer Institute (NCI) method [30]. Complete details of the NCI method are shown elsewhere, and the SAS macros necessary to estimate the distribution of a nutrient intake below a certain threshold are available on the NCI website [30]. Time trends in the mean dietary, total magnesium intakes, and prevalence of magnesium intake inadequacy were examined by survey-weighted linear regression models. The statistical significance of trends was assessed by treating survey year as a continuous independent variable. The trends were tested in the overall population, as well as in each subpopulation stratified by gender, ethnicity origins, age and PIR categories. All statistical tests were based on two-sided probability and a significance level of $p<0.05$.

\section{Results}

Over the survey cycles, the proportion of Hispanic adults aged 35-49 years old increased, while the proportion of Hispanic adults aged 50 years and above decreased (Table 1). The percentage of Hispanic males slightly increased over the study period. The proportion of Mexican American adults increased from $46.3 \%$ in $1999-2000$ to $61.1 \%$ in 2013-2014, and other Hispanic adults decreased. The proportion of Hispanic adults with PIR < 1.0 increased from $25.4 \%$ in $1999-2000$ to 31.1\% in 2013-2014.

Trends in mean dietary and total intakes of magnesium among Hispanic adults $\geq 20$ years old and subpopulations from 1999 to 2014 are presented in Tables 2 and 3, respectively. For the daily dietary magnesium intake, the average intake significantly increased from $275.06 \mathrm{mg}$ in 1999-2000 to 319.21 $\mathrm{mg}$ in 2013-2014, with an improvement of $16.1 \%$ in overall Hispanic adults aged $\geq 20$ years old ( $p$-trend $<0.001$ ) (Table 2). In overall Hispanic adults, the average dietary magnesium intake increased between 1999-2000 and 2005-2006, slightly decreased between 2005-2006 and 2007-2008, thereafter increased and peaked in 2013-2014. Thus, there were significant trends in the mean dietary magnesium intake in all subgroups (all $p$-trends $<0.001$ ). Significant increases in dietary magnesium intake were further observed among both genders, all ages, both Hispanic-origin subgroups, and all PIR levels.

For the trend in total magnesium intake, a similar pattern with the trend in dietary magnesium intake was found across the survey cycles among overall Hispanic adults $\geq 20$ years old (Table 3 ). The mean intake increased from $303.89 \mathrm{mg} /$ day in 1999-2000 to $331.78 \mathrm{mg} /$ day in 2013-2014, with an improvement of $9.2 \%$ among all Hispanic adults $\geq 20$ years old ( $p$-trend $<0.001$ ). Furthermore, the mean total magnesium intake significantly increased among Hispanic adults in both genders, all age subgroups, and both Hispanic-origin subgroups ( $p$-trends $<0.001)$. By PIR levels, total magnesium intakes were significantly increased among Hispanic adults, with PIR lower than 1.85 across survey cycles, while a significant reduction in total magnesium intake was observed among Hispanic adults with PIR $\geq 1.85$ between 1999-2000 and 2013-2014 ( $p$-trend $<0.001$ ). In all survey cycles, females, other Hispanics, adults aged 65 years and above, and adults with PIR $<1.0$ tended to have lower dietary and total magnesium intakes. 
Trends in the proportion of Hispanic adults with dietary and total magnesium intake not meeting the RDA were further evaluated by gender and age groups. Significant decreases were observed for the estimated prevalence of Hispanic males $\geq 20$ years old consuming dietary and total magnesium intakes less than the RDA ( $p$ for linear trend < 0.05) (Figure 1). Between 2003-2004 and 2013-2014, the prevalence of inadequate magnesium intake from foods decreased from $86 \%$ to $73.7 \%$, and the prevalence of total magnesium intake less than the RDA reduced from $80.1 \%$ to $71.4 \%$. By age groups, improvement of total magnesium intake was modest among Hispanic males aged 31-64 years ( $p$ for linear trend $=0.05$ ), with the prevalence of total magnesium intake below the RDA decreasing from $82.3 \%$ to $74.3 \%$ between 2003-2004 and 2013-2014 (Figure 2). Although the prevalence of total magnesium intake less than the RDA also decreased among Hispanic males in 20-30-year and $\geq 65$-year groups, the changes were not statistically significant.

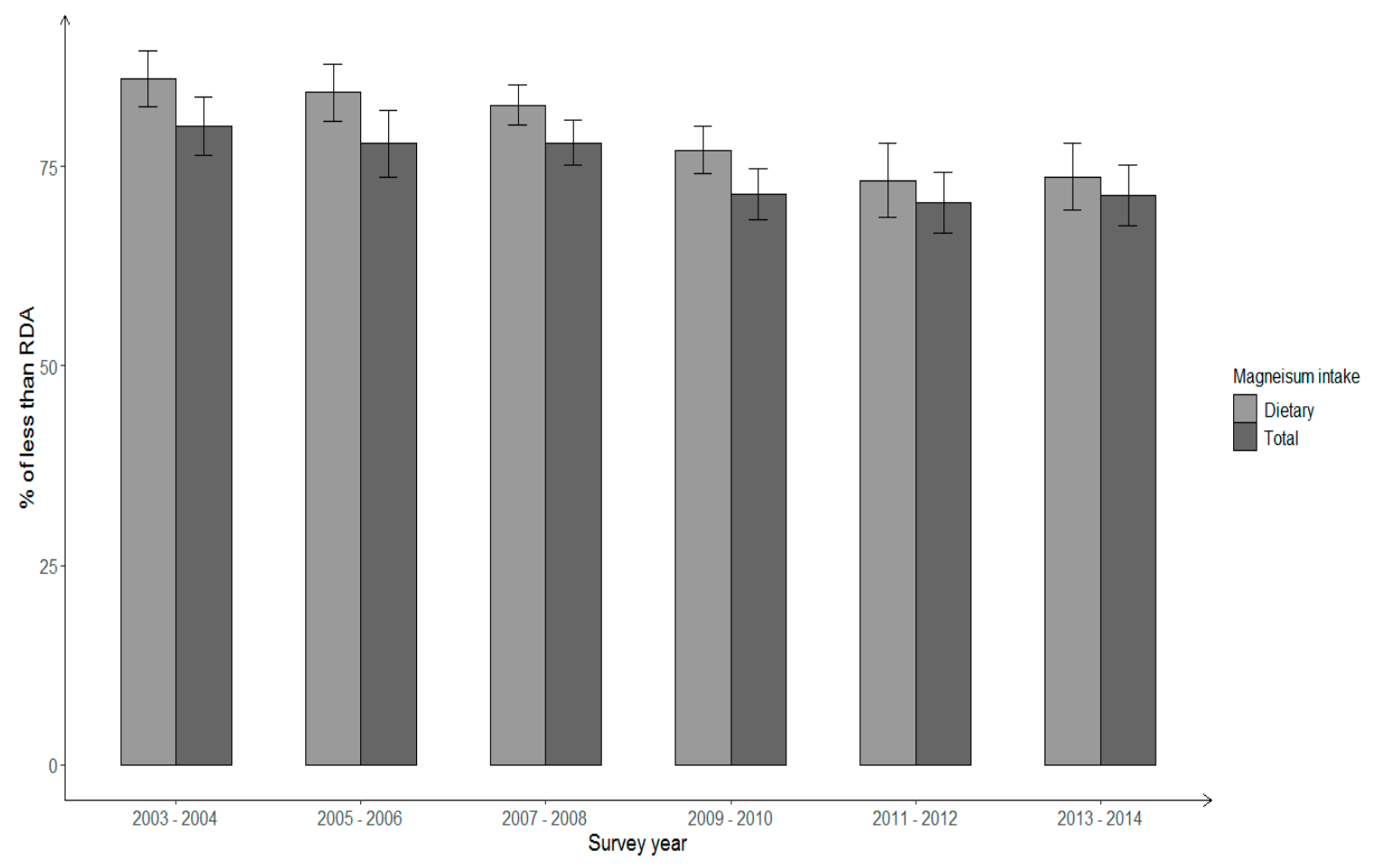

Figure 1. Percentage of insufficient dietary and total magnesium intake among Hispanic males aged $\geq 20$ years across NHANES survey years 2003-2014.

Among overall Hispanic females $\geq 20$ years, the prevalence of magnesium intake below the RDA decreased from $80.8 \%$ in $2003-2004$ to $75.3 \%$ in 2013-2014 for dietary intake, and the corresponding change for total magnesium intake was $74.4 \%$ to $70.8 \%$; however, the changes were not statistically significant ( $p$ for linear trend $>0.05$ ) (Figure 3 ). In addition, there was no significant trend in the prevalence of Hispanic females not meeting the RDA for total magnesium intake in all age groups (figure not shown). The prevalence with total magnesium intake less than the RDA decreased from $76.1 \%$ in $2003-2004$ to $66.6 \%$ in 2013-2014 among Hispanic females aged 31-64 years; whereas, it increased among females 20-30-year-old (from 73.9\% to 76.7\%) and females aged $\geq 65$ years old (from 59.6\% to 69.5\%), reflecting differences by age. In addition, the prevalence of insufficient total magnesium intake in different age groups varied by gender. Over time, among Hispanic adults less than 65 years, the proportion of males with total magnesium intake not meeting the RDA tended to be less than the prevalence among females. However, in the senior group ( $\geq 65$ years) the prevalence was higher among Hispanic males than among females. In 2013-2014, more than 70\% of Hispanic adults still had a total magnesium intake below the RDA regardless of their age and gender. 
Table 1. Demographics of Hispanic adults aged $\geq 20$ years by National Health and Nutrition Examination Survey (NHANES) cycle, 1999-2014 $(n=9304)$.

\begin{tabular}{|c|c|c|c|c|c|c|c|c|}
\hline Demographics $^{a}$ & $\begin{array}{l}1999-2000 \\
(n=1288)\end{array}$ & $\begin{array}{l}2001-2002 \\
(n=1087)\end{array}$ & $\begin{array}{c}2003-2004 \\
(n=928)\end{array}$ & $\begin{array}{c}2005-2006 \\
(n=911)\end{array}$ & $\begin{array}{l}2007-2008 \\
(n=1475)\end{array}$ & $\begin{array}{l}2009-2010 \\
(n=1603)\end{array}$ & $\begin{array}{c}2011-2012 \\
(n=914)\end{array}$ & $\begin{array}{l}2013-2014 \\
(n=1098)\end{array}$ \\
\hline \multicolumn{9}{|l|}{ Age, years } \\
\hline $20-34$ & $314(39.0)$ & $343(41.1)$ & $231(39.4)$ & $324(42.1)$ & $396(38.5)$ & $426(37.7)$ & $252(39.2)$ & $277(37.2)$ \\
\hline $35-49$ & 345 (31.9) & $335(34.8)$ & $244(37.0)$ & $271(34.7)$ & $390(33.9)$ & $477(36.4)$ & $240(32.6)$ & $334(35.9)$ \\
\hline $50-64$ & $318(18.9)$ & $209(14.8)$ & $183(14.6)$ & $183(15.6)$ & $431(18.8)$ & $440(16.9)$ & $273(19.7)$ & $300(18.3)$ \\
\hline$\geq 65$ & $311(10.2)$ & $200(9.3)$ & $270(8.9)$ & $133(7.6)$ & $258(8.8)$ & $260(9.1)$ & $149(8.4)$ & $187(8.6)$ \\
\hline \multicolumn{9}{|l|}{ Gender } \\
\hline Male & $633(49.2)$ & $574(53.0)$ & $488(53.8)$ & $491(54.1)$ & $711(53.8)$ & $779(53.4)$ & $471(52.3)$ & $528(51.4)$ \\
\hline Female & $655(50.8)$ & $513(47.0)$ & $440(46.2)$ & $420(45.9)$ & $764(46.2)$ & $824(46.6)$ & $443(47.7)$ & $570(48.6)$ \\
\hline \multicolumn{9}{|l|}{ Race/Ethnicity } \\
\hline Mexican American & $1037(46.3)$ & $902(52.8)$ & $808(68.1)$ & $784(68.8)$ & $894(63.1)$ & $1029(62.8)$ & $456(55.1)$ & $652(61.1)$ \\
\hline $\begin{array}{c}\text { Other Hispanic } \\
\text { PIR b }\end{array}$ & \multicolumn{7}{|c|}{$\mathrm{PIR}^{\mathrm{b}}$} & $446(38.9)$ \\
\hline$<1.0$ & $307(25.4)$ & $256(28.2)$ & $267(27.4)$ & $266(27.5)$ & $364(28.5)$ & $436(33.3)$ & $264(32.1)$ & $297(30.1)$ \\
\hline $1.0-1.84$ & $374(32.7)$ & $301(28.1)$ & $252(25.4)$ & $239(29.4)$ & $376(29.4)$ & $387(28.0)$ & $222(25.3)$ & $256(26.8)$ \\
\hline$\geq 1.85$ & 398 (41.9) & $450(43.7)$ & $359(47.2)$ & 347 (43.2) & $553(42.1)$ & $537(38.7)$ & $344(42.6)$ & 413 (43.2) \\
\hline \multicolumn{9}{|l|}{ Supplement use } \\
\hline Yes & $291(25.5)$ & $255(22.1)$ & $244(23.9)$ & $206(23.8)$ & $335(20.6)$ & $367(21.9)$ & 187 (19.7) & $226(18.7)$ \\
\hline
\end{tabular}

a Values are presented as frequency (weighted percentages); ${ }^{\mathrm{b}}$ the numbers may not sum to the total number of participants due to missing data. PIR: poverty income ratio. 
Table 2. Trends in daily dietary magnesium intake (mg/day) among Hispanic adults aged $\geq 20$ years, the National Health and Nutrition Examination Survey (NHANES) $1999-2014^{*}(n=9304)$.

\begin{tabular}{|c|c|c|c|c|c|c|c|c|c|}
\hline Factors & $\begin{array}{l}1999-2000 \\
(n=1288)\end{array}$ & $\begin{array}{l}2001-2002 \\
(n=1087)\end{array}$ & $\begin{array}{c}2003-2004 \\
(n=928)\end{array}$ & $\begin{array}{c}2005-2006 \\
(n=911)\end{array}$ & $\begin{array}{l}2007-2008 \\
(n=1475)\end{array}$ & $\begin{array}{l}2009-2010 \\
(n=1603)\end{array}$ & $\begin{array}{c}2011-2012 \\
(n=914)\end{array}$ & $\begin{array}{l}2013-2014 \\
(n=1098)\end{array}$ & $\begin{array}{c}p \text {-Value for } \\
\text { Trend }{ }^{a}\end{array}$ \\
\hline $\begin{array}{l}\text { Overall } \\
\text { Gender }\end{array}$ & $275.06 \pm 7.20$ & $275.72 \pm 7.49$ & $290.87 \pm 6.15$ & $302.80 \pm 7.21$ & $296.40 \pm 7.45$ & $307.19 \pm 5.35$ & $315.06 \pm 8.69$ & $319.21 \pm 7.54$ & $<0.0001$ \\
\hline Male & $317.08 \pm 10.31$ & $317.92 \pm 6.91$ & $328.15 \pm 10.28$ & $333.57 \pm 9.31$ & $336.31 \pm 7.88$ & $354.59 \pm 8.33$ & $359.79 \pm 11.90$ & $364.68 \pm 9.79$ & $<0.0001$ \\
\hline Female & $236.62 \pm 11.98$ & $227.57 \pm 9.69$ & $250.07 \pm 7.44$ & $265.70 \pm 7.18$ & $250.86 \pm 8.38$ & $255.87 \pm 6.39$ & $266.02 \pm 7.63$ & $272.82 \pm 6.86$ & $<0.0001$ \\
\hline Race/Ethnicity & & & & & & & & & \\
\hline Mexican American & $282.49 \pm 8.39$ & $292.79 \pm 5.98$ & $299.91 \pm 7.61$ & $311.02 \pm 9.29$ & $299.20 \pm 9.31$ & $320.87 \pm 7.02$ & $327.79 \pm 11.96$ & $327.83 \pm 10.79$ & $<0.0001$ \\
\hline $\begin{array}{l}\text { Other Hispanic } \\
\text { Age, years }\end{array}$ & $269.09 \pm 9.93$ & $254.14 \pm 8.50$ & $267.99 \pm 13.01$ & $279.56 \pm 14.18$ & $291.65 \pm 9.43$ & $284.98 \pm 6.86$ & $299.05 \pm 10.40$ & $305.20 \pm 10.29$ & $<0.0001$ \\
\hline $20-34$ & $284.31 \pm 11.01$ & $278.37 \pm 8.40$ & $319.75 \pm 12.95$ & $301.16 \pm 8.93$ & $293.57 \pm 12.46$ & $316.10 \pm 9.78$ & $320.33 \pm 11.77$ & $324.83 \pm 13.60$ & $<0.0001$ \\
\hline $35-49$ & $283.87 \pm 10.34$ & $278.09 \pm 8.34$ & $278.93 \pm 12.54$ & $317.90 \pm 9.35$ & $318.85 \pm 10.85$ & $318.74 \pm 10.03$ & $329.81 \pm 11.60$ & $319.28 \pm 4.37$ & $<0.0001$ \\
\hline $50-64$ & $264.81 \pm 18.80$ & $290.35 \pm 16.76$ & $264.00 \pm 13.11$ & $299.99 \pm 20.03$ & $290.48 \pm 7.83$ & $290.20 \pm 5.95$ & $304.61 \pm 12.25$ & $326.90 \pm 12.14$ & $<0.0001$ \\
\hline $\begin{array}{l}\geq 65 \\
\text { PIR }\end{array}$ & $231.40 \pm 18.15$ & $231.57 \pm 12.79$ & $255.64 \pm 13.90$ & $259.46 \pm 18.71$ & $241.18 \pm 6.21$ & $258.69 \pm 7.797$ & $264.52 \pm 10.47$ & $280.61 \pm 10.67$ & $<0.0001$ \\
\hline$<1.0$ & $240.83 \pm 11.90$ & $240.97 \pm 15.78$ & $261.40 \pm 12.47$ & $290.48 \pm 17.98$ & $277.88 \pm 16.53$ & $300.17 \pm 8.08$ & $302.61 \pm 14.66$ & $298.43 \pm 9.15$ & $<0.0001$ \\
\hline $1.0-1.84$ & $263.40 \pm 13.96$ & $273.43 \pm 11.46$ & $305.30 \pm 12.46$ & $298.77 \pm 12.12$ & $283.43 \pm 12.84$ & $309.75 \pm 7.59$ & $320.73 \pm 17.25$ & $346.06 \pm 13.36$ & $<0.0001$ \\
\hline$\geq 1.85$ & $303.08 \pm 13.07$ & $297.16 \pm 8.55$ & $299.52 \pm 10.25$ & $308.57 \pm 11.91$ & $316.34 \pm 6.28$ & $310.82 \pm 10.69$ & $320.48 \pm 9.47$ & $318.31 \pm 9.44$ & $<0.0001$ \\
\hline
\end{tabular}

* Values are presented as weighted means \pm standard error. ${ }^{a} p$ value from linear regression by modeling survey period as a continuous variable. 
Table 3. Trends in total magnesium intake (mg/day) among Hispanic adults aged $\geq 20$ years, the National Health and Nutrition Examination Survey (NHANES) $1999-2014^{*}(n=9304)$.

\begin{tabular}{|c|c|c|c|c|c|c|c|c|c|}
\hline \multirow{2}{*}{ Factors } & 1999-2000 & 2001-2002 & $2003-2004$ & $2005-2006$ & $2007-2008$ & $2009-2010$ & 2011-2012 & 2013-2014 & \multirow{2}{*}{$\begin{array}{l}p \text {-Value for } \\
\text { Trend }^{\text {a }}\end{array}$} \\
\hline & $(n=1288)$ & $(n=1087)$ & $(n=928)$ & $(n=911)$ & $(n=1475)$ & $(n=1603)$ & $(n=914)$ & $(n=1098)$ & \\
\hline Overall & $303.89 \pm 7.35$ & $296.74 \pm 6.73$ & $312.43 \pm 5.95$ & $323.68 \pm 8.36$ & $313.97 \pm 8.27$ & $323.28 \pm 5.78$ & $329.90 \pm 9.18$ & $331.78 \pm 8.11$ & $<0.0001$ \\
\hline \multicolumn{10}{|l|}{ Gender } \\
\hline Male & $343.22 \pm 8.06$ & $340.40 \pm 6.67$ & $347.55 \pm 11.47$ & $353.72 \pm 10.69$ & $356.22 \pm 10.95$ & $370.19 \pm 8.65$ & $372.67 \pm 12.35$ & $373.03 \pm 10.47$ & $<0.0001$ \\
\hline Female & $267.92 \pm 14.48$ & $246.92 \pm 9.48$ & $273.99 \pm 6.32$ & $287.47 \pm 7.92$ & $265.77 \pm 7.56$ & $272.49 \pm 8.23$ & $283.00 \pm 7.77$ & $289.70 \pm 8.37$ & $<0.0001$ \\
\hline \multicolumn{10}{|l|}{ Race/Ethnicity } \\
\hline Mexican American & $307.88 \pm 8.78$ & $316.66 \pm 6.72$ & $320.00 \pm 8.29$ & $331.09 \pm 10.62$ & $312.56 \pm 10.21$ & $338.18 \pm 7.18$ & $343.74 \pm 12.75$ & $338.67 \pm 11.30$ & $<0.0001$ \\
\hline Other Hispanic & $300.69 \pm 9.82$ & $271.56 \pm 7.78$ & $293.26 \pm 12.98$ & $302.75 \pm 15.14$ & $316.34 \pm 13.46$ & $299.08 \pm 7.86$ & $312.48 \pm 11.03$ & $320.59 \pm 10.51$ & $<0.0001$ \\
\hline \multicolumn{10}{|l|}{ Age, years } \\
\hline $20-34$ & $302.85 \pm 10.52$ & $292.77 \pm 6.24$ & $329.04 \pm 12.58$ & $315.91 \pm 11.11$ & $311.09 \pm 14.78$ & $328.27 \pm 9.71$ & $325.15 \pm 11.89$ & $330.46 \pm 13.58$ & $<0.0001$ \\
\hline $35-49$ & $318.30 \pm 12.99$ & $299.24 \pm 9.86$ & $297.57 \pm 11.63$ & $340.48 \pm 12.40$ & $333.25 \pm 10.27$ & $332.38 \pm 11.35$ & $353.80 \pm 14.62$ & $330.91 \pm 5.85$ & $<0.0001$ \\
\hline $50-64$ & $305.08 \pm 25.58$ & $322.17 \pm 15.66$ & $306.78 \pm 20.91$ & $320.92 \pm 15.85$ & $312.61 \pm 8.53$ & $316.09 \pm 7.75$ & $324.81 \pm 14.65$ & $341.32 \pm 13.67$ & 0.0010 \\
\hline$\geq 65$ & $260.98 \pm 12.22$ & $264.64 \pm 15.28$ & $305.24 \pm 22.85$ & $301.27 \pm 22.14$ & $260.67 \pm 7.91$ & $281.71 \pm 7.17$ & $278.84 \pm 12.93$ & $320.26 \pm 21.53$ & 0.0046 \\
\hline \multicolumn{10}{|l|}{ PIR } \\
\hline$<1.0$ & $263.48 \pm 11.03$ & $265.28 \pm 15.79$ & $271.48 \pm 13.14$ & $297.22 \pm 18.19$ & $286.04 \pm 16.83$ & $311.95 \pm 8.36$ & $310.76 \pm 14.86$ & $308.53 \pm 9.74$ & $<0.0001$ \\
\hline $1.0-1.84$ & $283.82 \pm 13.83$ & $287.52 \pm 9.48$ & $330.10 \pm 11.56$ & $320.32 \pm 9.39$ & $299.26 \pm 13.56$ & $323.62 \pm 8.21$ & $328.20 \pm 17.03$ & $361.14 \pm 12.52$ & $<0.0001$ \\
\hline$\geq 1.85$ & $341.34 \pm 13.44$ & $323.35 \pm 9.67$ & $326.78 \pm 10.91$ & $338.44 \pm 13.24$ & $343.16 \pm 9.64$ & $333.50 \pm 12.57$ & $346.33 \pm 10.35$ & $331.97 \pm 10.37$ & $<0.0001$ \\
\hline
\end{tabular}

* Values are presented as weighted means \pm standard error. ${ }^{\text {a }} p$ value from linear regression by modeling survey period as a continuous variable. 


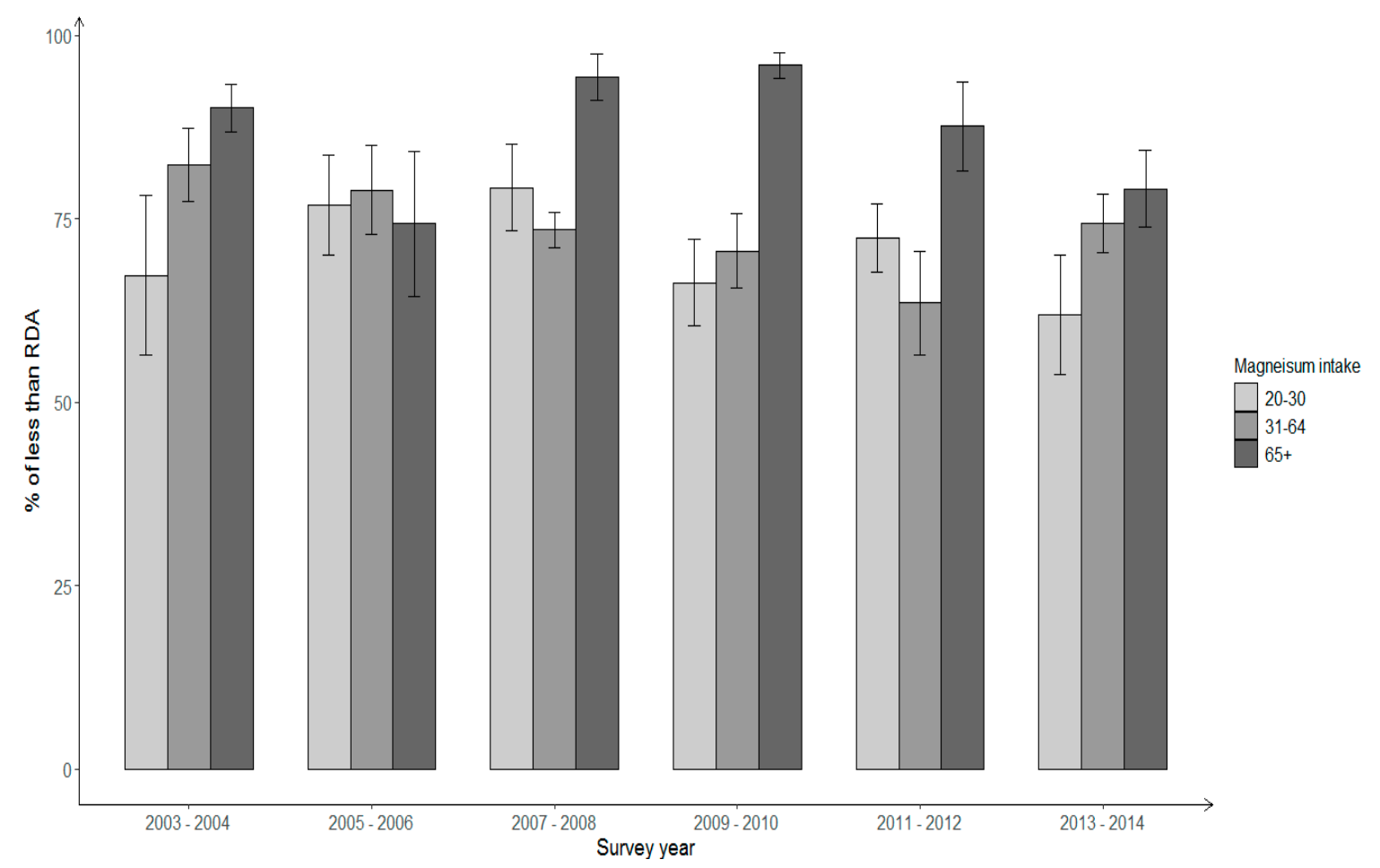

Figure 2. Percentage of insufficient total magnesium intake among Hispanic males by age groups across NHANES survey years 2003-2014.

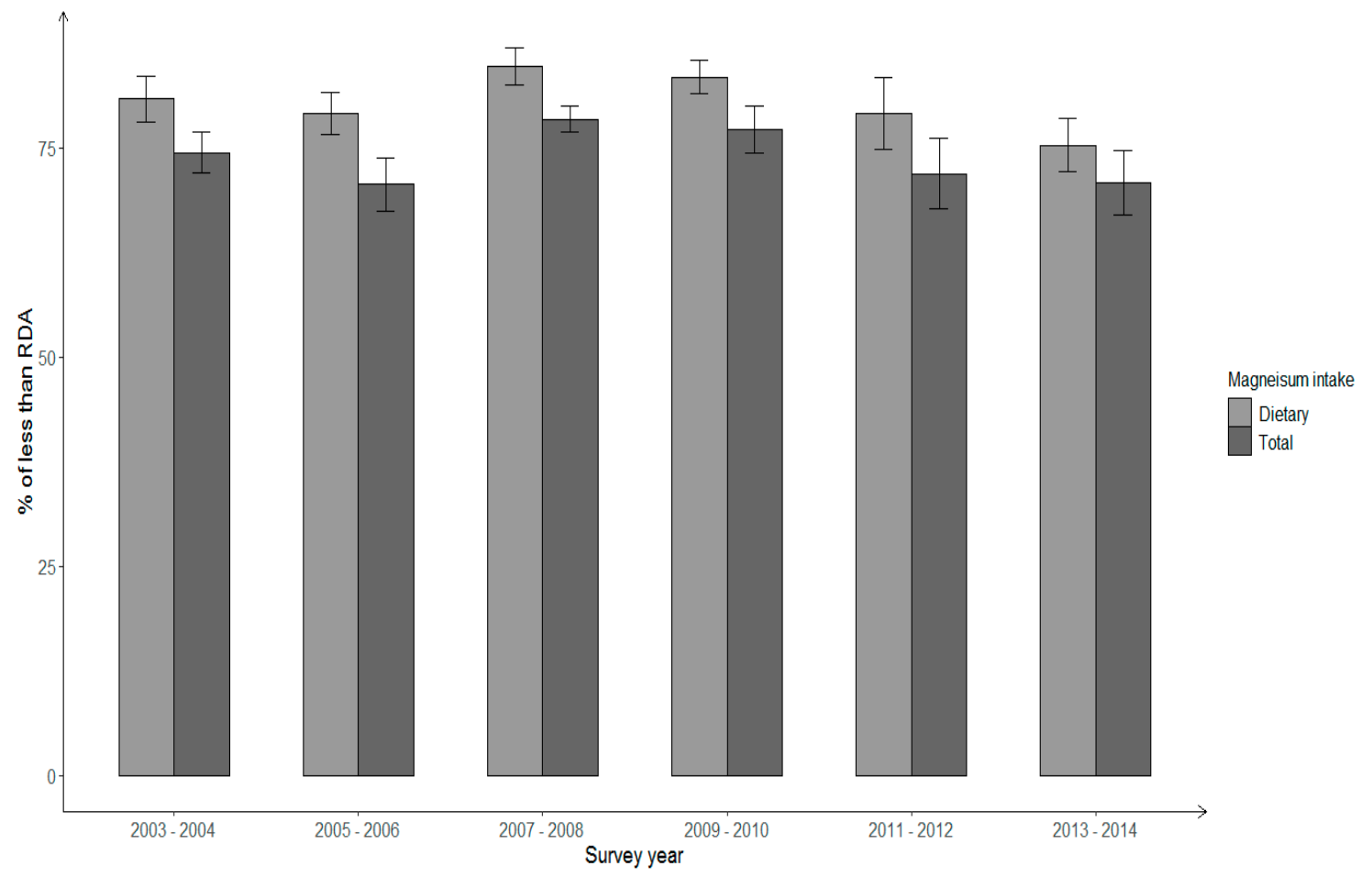

Figure 3. Percentage of insufficient dietary and total magnesium intake among Hispanic females aged $\geq 20$ years across NHANES survey years 2003-2014.

\section{Discussion}

Based on nationally representative data collected between 1999-2000 and 2013-2014, magnesium intake improved significantly among U.S. Hispanic adults, with $16.1 \%$ improvement for the mean 
dietary magnesium intake and 9.2\% improvement for the mean total magnesium intake. Despite observed overall improvements, trends in magnesium intake from all sources varied by PIR levels, with a trend of reduction among Hispanic adults with a higher PIR. Meanwhile, there were persistent comparative differences in dietary and total magnesium intakes by gender, age and ethnicity subgroups, and PIR levels, with lower intakes among Hispanic females, other Hispanics, adults aged $\geq 65$ years, and adults with lower PIR over the survey cycles. Furthermore, although magnesium intake increased over the study period, $71.4 \%$ and $70.8 \%$ of Hispanic males and females had total magnesium intake less than the RDA in 2013-2014, respectively.

Between 1999-2000 and 2013-2014, total magnesium intake increased significantly among Hispanic adults with PIR $<1.85$ but declined among those with PIR $\geq 1.85$. One possible explanation for this difference in trend may be that Hispanic adults with high family income are more likely to adopt the standard American diet, which is generally characterized by a high intake of fat and sugar, and low consumption of nutrient-dense food [31]. A previous study found that Hispanic women with a higher education attainment were more likely to have a higher intake of fat [32]. Because PIR level is positively correlated with education attainment, Hispanic adults with a higher PIR level may be more likely to be exposed to typical American diets. These findings suggest that socioeconomic factors such as education and family income may be an important proxy of acculturation.

Between 1999-2000 and 2013-2014, magnesium intake increased significantly among Hispanic males and females, while Hispanic females persistently had lower intakes than Hispanic males. The reason for the gender difference in magnesium intake is unknown. Possible explanations for the gender differences include different biological requirements for men and women to maintain magnesium homeostasis in the body [6], and differences in body size, and physical activities between men and women [33], which could lead to gender differences in magnesium intake.

Magnesium is widely distributed in plant and animal foods [6,7]; however, a large proportion of U.S. adults do not consume a sufficient amount of magnesium as they are recommended [19]. Dietary supplementation is an important source of magnesium, and the most commonly used adult multivitamin/minerals contain $50 \mathrm{mg}$ of magnesium per serving [34]. In further analysis, we found that the prevalence of using magnesium supplements remained low among Hispanic adults, ranging from $18.7 \%$ to $25.5 \%$ across survey years. Hispanic adults who used magnesium supplements consistently reported higher dietary magnesium intake across survey cycles compared to those who did not use a magnesium supplement (data not shown). In 2013-2014, the last study survey cycle, the average daily intakes of dietary magnesium were $405.46 \mathrm{mg}$ for Hispanic male supplement users and $276.17 \mathrm{mg}$ for female supplement users, but the average intakes of dietary magnesium were only $357.79 \mathrm{mg} /$ day and $271.82 \mathrm{mg} /$ day for Hispanic male and female supplement non-users, respectively. Previous studies have reported that calcium supplement users were more likely to have a higher dietary intake of calcium than those who do not use supplemental calcium [35]. These findings suggest that individuals who consume dietary supplements (i.e., magnesium or calcium) may have healthier dietary habits. The high prevalence of supplement non-users in Hispanic adults over the survey cycles may partially explain why the prevalence of magnesium intake below the RDA remained high in 2013-2014.

One strength of our study is the use of data from the NHANES with a nationally representative sample of the U.S. population, and oversampled Hispanic subjects, which provided a sufficient sample of Hispanic adults from different demographic subgroups to provide sufficient statistical power. Several limitations should also be mentioned. Self-reported supplement intake is subject to recall bias; however, participants were asked to provide their supplement bottles during the in-person interviewing. Although multiple $24 \mathrm{~h}$ dietary recalls are used as a gold standard measure in nutritional epidemiological studies [30], a one-time $24 \mathrm{~h}$ dietary recall may not capture long-term magnesium intake. Self-reported dietary recall may result in both random and systematic errors with the potential for recall bias to occur [36].

In conclusion, our results showed improvements in both dietary and total magnesium intakes among U.S. Hispanic adults between 1999 and 2014; however, magnesium consumption remains 
suboptimal among the U.S. Hispanic population. Insufficient magnesium intake has been associated with a higher risk of type 2 diabetes [11,12] and other chronic diseases [13,17], and there is an increase in the rate of type 2 diabetes in the U.S. Hispanic population [20]. Findings from this study may inform discussions on emerging successes, areas for more attention, and opportunities to develop appropriate, multi-level prevention approaches to improve magnesium intakes from diet and dietary supplementation for Hispanic adults living in the United States.

Author Contributions: J.L. carried out the statistical analyses and wrote a draft of the manuscript. M.-H.T. designed the current study and supervise the study process. Y.H., Q.D., K.G.F., S.C. and M.-H.T. contributed to statistical analysis, data interpretation, and the critical review of the manuscript. All authors read and approved the final manuscript.

Funding: This work was supported by the National Institute on Minority Health and Health Disparities of the National Institute of Health under Award U54MD006882. The content is solely the responsibility of the authors and does not necessarily represent the official views of the National Institute of Health.

Acknowledgments: We thank the investigators, the staff and the participants of the NHANES for their valuable contribution.

Conflicts of Interest: The authors declare no conflict of interest.

\section{References}

1. Rosanoff, A.; Dai, Q.; Shapses, S.A. Essential nutrient interactions: Does low or suboptimal magnesium status interact with vitamin d and/or calcium status? Adv. Nutr. 2016, 7, 25-43. [CrossRef] [PubMed]

2. Volpe, S.L. Magnesium in disease prevention and overall health. Adv. Nutr. 2013, 4, 378S-383S. [CrossRef] [PubMed]

3. Zhang, Y.; Xun, P.; Wang, R.; Mao, L.; He, K. Can magnesium enhance exercise performance? Nutrients 2017, 9, 946. [CrossRef]

4. Hayhoe, R.P.; Lentjes, M.A.; Luben, R.N.; Khaw, K.T.; Welch, A.A. Dietary magnesium and potassium intakes and circulating magnesium are associated with heel bone ultrasound attenuation and osteoporotic fracture risk in the epic-norfolk cohort study. Am. J. Clin. Nutr. 2015, 102, 376-384. [CrossRef] [PubMed]

5. de Baaij, J.H.; Hoenderop, J.G.; Bindels, R.J. Magnesium in man: Implications for health and disease. Physiol. Rev. 2015, 95, 1-46. [CrossRef] [PubMed]

6. Institute of Medicine (US) Standing Committee on the Scientific Evaluation of Dietary Reference Intakes. Dietary Reference Intakes for Calcium, Phosphorus, Magnesium, Vitamin D, and Fluoride; National Academies Press: Washington, DC, USA, 1997.

7. Ross, A.C.; Caballero, B.; Cousins, R.J.; Tucker, K.L.; Ziegler, T.R. Modern Nutrition in Health and Disease, 11th ed.; Jones \& Bartlett Learning: Philadelphia, PA, USA, 2012.

8. Solati, M.; Ouspid, E.; Hosseini, S.; Soltani, N.; Keshavarz, M.; Dehghani, M. Oral magnesium supplementation in type ii diabetic patients. Med. J. Islamic Repub. Iran 2014, 28, 67.

9. He, K.; Liu, K.; Daviglus, M.L.; Morris, S.J.; Loria, C.M.; Van Horn, L.; Jacobs, D.R., Jr.; Savage, P.J. Magnesium intake and incidence of metabolic syndrome among young adults. Circulation 2006, 113, 1675-1682. [CrossRef]

10. Huang, J.-H.; Lu, Y.-F.; Cheng, F.-C.; Lee, J.N.-Y.; Tsai, L.-C. Correlation of magnesium intake with metabolic parameters, depression and physical activity in elderly type 2 diabetes patients: A cross-sectional study. Nutr. J. 2012, 11, 41. [CrossRef] [PubMed]

11. Hopping, B.N.; Erber, E.; Grandinetti, A.; Verheus, M.; Kolonel, L.N.; Maskarinec, G. Dietary fiber, magnesium, and glycemic load alter risk of type 2 diabetes in a multiethnic cohort in hawaii. J. Nutr. 2009, 140, 68-74. [CrossRef] [PubMed]

12. Hruby, A.; McKeown, N.; Song, Y.; Djoussé, L. Dietary magnesium and genetic interactions in diabetes and related risk factors: A brief overview of current knowledge. Nutrients 2013, 5, 4990-5011. [CrossRef]

13. Del Gobbo, L.C.; Imamura, F.; Wu, J.H.; de Oliveira Otto, M.C.; Chiuve, S.E.; Mozaffarian, D. Circulating and dietary magnesium and risk of cardiovascular disease: A systematic review and meta-analysis of prospective studies. Am. J. Clin. Nutr. 2013, 98, 160-173. [CrossRef] [PubMed]

14. Qu, X.; Jin, F.; Hao, Y.; Li, H.; Tang, T.; Wang, H.; Yan, W.; Dai, K. Magnesium and the risk of cardiovascular events: A meta-analysis of prospective cohort studies. PLOS ONE 2013, 8, e57720. [CrossRef] [PubMed]

15. Jahnen-Dechent, W.; Ketteler, M. Magnesium basics. Clin. Kidney J. 2012, 5, i3-i14. [CrossRef] [PubMed] 
16. Chen, G.; Pang, Z.; Liu, Q. Magnesium intake and risk of colorectal cancer: A meta-analysis of prospective studies. Eur. J. Clin. Nutr. 2012, 66, 1182. [CrossRef] [PubMed]

17. Ko, H.J.; Youn, C.H.; Kim, H.M.; Cho, Y.J.; Lee, G.H.; Lee, W.K. Dietary magnesium intake and risk of cancer: A meta-analysis of epidemiologic studies. Nutr. Cancer 2014, 66, 915-923. [CrossRef] [PubMed]

18. Agarwal, S.; Reider, C.; Brooks, J.R.; Fulgoni, V.L., III. Comparison of prevalence of inadequate nutrient intake based on body weight status of adults in the united states: An analysis of nhanes 2001-2008. J. Am. Coll. Nutr. 2015, 34, 126-134. [CrossRef]

19. U.S. Department of Health Human Services; U.S. Department of Agriculture. 2015-2020 Dietary Guidelines for American, 8th ed.; 2015. Available online: https://health.gov/dietaryguidelines/2015/guidelines/ (accessed on 3 June 2019).

20. Fryar, C.D.; Wright, J.D.; Eberhardt, M.S.; Dye, B.A. Trends in Nutrient Intakes and Chronic Health Conditions Among Mexican-American Adults, a 25-Year Profile: United States, 1982-2006. Natl Health Stat Report 2012, 28, 1-20.

21. Cason, K.; Nieto-Montenegro, S.; Chavez-Martinez, A. Food choices, food sufficiency practices, and nutrition education needs of hispanic migrant workers in pennsylvania. Top. Clin. Nutr. 2006, 21, 145-158. [CrossRef]

22. Haile, R.W.; John, E.M.; Levine, A.J.; Cortessis, V.K.; Unger, J.B.; Gonzales, M.; Ziv, E.; Thompson, P.; Spruijt-Metz, D.; Tucker, K.L. A review of cancer in us hispanic populations. Cancer Prev. Res. 2012, 5, 150-163. [CrossRef]

23. Ford, E.S.; Giles Wh Fau-Dietz, W.H.; Dietz, W.H. Prevalence of the metabolic syndrome among us adults: Findings from the third national health and nutrition examination survey. JAMA 2002, 287, 356-359. [CrossRef]

24. Menke, A.; Casagrande, S.; Geiss, L.; Cowie, C.C. Prevalence of and trends in diabetes among adults in the united states, 1988-2012 prevalence of and trends in diabetes among us adultsprevalence of and trends in diabetes among us adults. JAMA 2015, 314, 1021-1029. [CrossRef] [PubMed]

25. Johnson, C.L.; Dohrmann, S.M.; Burt, V.; Mohadjer, L.K. National health and nutrition examination survey: Sample design, 2011-2014. Vital Health Stat. 2 2014, 162, 1-33.

26. Centers for Disease Control and Prevention. National Health and Nutrition Examination Survey Mec in-Person Dietary Interviewers Procedures Manual; Department of Health and Human Services (US): Hyattsville, MD, USA, 2002.

27. Blanton, C.A.; Moshfegh, A.J.; Baer, D.J.; Kretsch, M.J. The usda automated multiple-pass method accurately estimates group total energy and nutrient intake. J. Nutr. 2006, 136, 2594-2599. [CrossRef] [PubMed]

28. Moshfegh, A.J.; Rhodes, D.G.; Baer, D.J.; Murayi, T.; Clemens, J.C.; Rumpler, W.V.; Paul, D.R.; Sebastian, R.S.; Kuczynski, K.J.; Ingwersen, L.A. The us department of agriculture automated multiple-pass method reduces bias in the collection of energy intakes. Am. J. Clin. Nutr. 2008, 88, 324-332. [CrossRef] [PubMed]

29. Ahluwalia, N.; Dwyer, J.; Terry, A.; Moshfegh, A.; Johnson, C. Update on nhanes dietary data: Focus on collection, release, analytical considerations, and uses to inform public policy. Adv. Nutr. 2016, 7, 121-134. [CrossRef] [PubMed]

30. Tooze, J.A.; Midthune, D.; Dodd, K.W.; Freedman, L.S.; Krebs-Smith, S.M.; Subar, A.F.; Guenther, P.M.; Carroll, R.J.; Kipnis, V. A new statistical method for estimating the usual intake of episodically consumed foods with application to their distribution. J. Am. Diet. Assoc. 2006, 106, 1575-1587. [CrossRef] [PubMed]

31. Halton, T.L.; Willett, W.C.; Liu, S.; Manson, J.E.; Stampfer, M.J.; Hu, F.B. Potato and french fry consumption and risk of type 2 diabetes in women. Am. J. Clin. Nutr. 2006, 83, 284-290. [CrossRef]

32. Bowen, D.J.; Jabson, J.M.; Barrington, W.E.; Littman, A.J.; Patrick, D.L.; Moudon, A.V.; Albano, D.; Beresford, S.A.A. Environmental and individual predictors of healthy dietary behaviors in a sample of middle aged hispanic and caucasian women. Int. J. Environ. Res. Public Health 2018, 15, 2277. [CrossRef]

33. Welch, A.A.; Skinner, J.; Hickson, M. Dietary magnesium may be protective for aging of bone and skeletal muscle in middle and younger older age men and women: Cross-sectional findings from the uk biobank cohort. Nutrients 2017, 9, 1189. [CrossRef]

34. Andrews, K.W.; Gusev, P.A.; Dang, P.; Savarala, S.; Oh, L.; Atkinson, R.; McNeal, M. Adult Multivitamin/Mineral (Amvm-2017) Dietary Supplement Study Research Summary; 2017. Available online: https://dietarysupplementdatabase.usda.nih.gov/dsid_database/Res\%20Summ\%20DSID\%204\% 20Adult\%20MVM-8-2-17\%20final.pdf (accessed on 21 May 2019). 
35. Bailey, R.L.; Fulgoni III, V.L.; Keast, D.R.; Dwyer, J.T. Dietary supplement use is associated with higher intakes of minerals from food sources. Am. J. Clin. Nutr. 2011, 94, 1376-1381. [CrossRef]

36. Roark, R.A.; Niederhauser, V.P. Fruit and vegetable intake: Issues with definition and measurement. Public Health Nutr. 2013, 16, 2-7. [CrossRef] [PubMed]

(C) 2019 by the authors. Licensee MDPI, Basel, Switzerland. This article is an open access article distributed under the terms and conditions of the Creative Commons Attribution (CC BY) license (http://creativecommons.org/licenses/by/4.0/). 